rumson

glyndîn

Glyndŵr University

Glyndŵr University Research Online

$1-1-2008$

\title{
Comparison of the mechanical and physical properties of a carbon fibre epoxy composite manufactured by resin transfer moulding using conventional and microwave heating
}

\author{
D A. Papargyris
}

Richard Day

GlyndwrUniversity, r.day@glyndwr.ac.uk

A Nesbitt

D Bakavos

Follow this and additional works at: http://epubs.glyndwr.ac.uk/aer_eng

Part of the Aerospace Engineering Commons, Manufacturing Commons, Polymer and Organic Materials Commons, Polymer Science Commons, and the Structural Materials Commons

\section{Recommended Citation}

Papargyris, D.A., Day, R.J., Nesbitt, A., Bakavos, D.(2008) “Comparison of the mechanical and physical properties of a carbon fibre epoxy composite manufactured by resin transfer moulding using conventional and microwave heating”. Composites Science and Technology, 68(7-8), 1854-1861 


\title{
Comparison of the mechanical and physical properties of a carbon fibre epoxy composite manufactured by resin transfer moulding using conventional and microwave heating
}

\begin{abstract}
Microwave processing holds great potential for improving current composite manufacturing techniques, substantially reducing cure cycle times, energy requirements and operational costs. In this paper, microwave heating was incorporated into the resin transfer moulding technique. Through the use of microwave heating, a $50 \%$ cure cycle time reduction was achieved. The mechanical and physical properties of the produced carbon fibre/epoxy composites were compared to those manufactured by conventional resin transfer moulding. Mechanical testing showed similar values of flexural moduli and flexural strength for the two types of composites after normalisation of the corresponding data to a common fibre volume fraction. A $9 \%$ increase of the interlaminar shear strength (ILSS) was observed for the microwave cured composites. This enhancement in ILSS is attributed to a lowering of resin viscosity in the initial stage of the curing process, which was also confirmed via scanning electron microscopy by means of improved fibre wetting and less fibre pull-out. Furthermore, both types of composites yielded minimal void content (
\end{abstract}

\section{Keywords}

Microwave curing; E. Resin transfer moulding; A. Polymer matrix composites; B. Interfacial strength; B. Mechanical properties

\section{Disciplines}

Aerospace Engineering | Engineering | Manufacturing | Polymer and Organic Materials | Polymer Science | Structural Materials

\section{Comments}

Copyright (C) 2008 Elsevier. All rights reserved. This is the author's final version of the work after peer review. The article was originally published in Composites Science and Technology in 2008 by Elsevier. The full published article can be found at http://dx.doi.org/10.1016/j.compscitech.2008.01.010.

This is a link to the publisher's website http://www.sciencedirect.co 


\section{Accepted Manuscript}

Comparison of the mechanical and physical properties of a carbon fibre epoxy composite manufactured by resin transfer moulding using conventional and microwave heating

D.A. Papargyris, R.J. Day, A. Nesbitt, D. Bakavos

PII: S0266-3538(08)00022-5

DOI: 10.1016/j.compscitech.2008.01.010

Reference: CSTE 3947

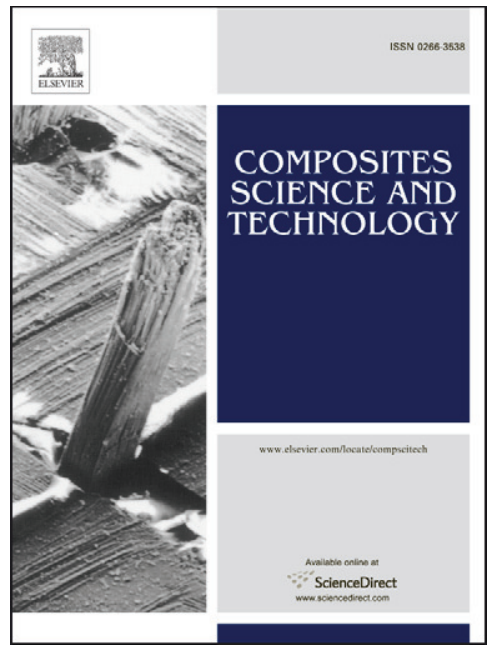

To appear in: $\quad$ Composites Science and Technology

Received Date: $\quad 28$ July 2007

Revised Date: $\quad 14$ January 2008

Accepted Date: $\quad 20$ January 2008

Please cite this article as: Papargyris, D.A., Day, R.J., Nesbitt, A., Bakavos, D., Comparison of the mechanical and physical properties of a carbon fibre epoxy composite manufactured by resin transfer moulding using conventional and microwave heating, Composites Science and Technology(2008), doi: 10.1016/j.compscitech.2008.01.010

This is a PDF file of an unedited manuscript that has been accepted for publication. As a service to our customers we are providing this early version of the manuscript. The manuscript will undergo copyediting, typesetting, and review of the resulting proof before it is published in its final form. Please note that during the production process errors may be discovered which could affect the content, and all legal disclaimers that apply to the journal pertain. 


\title{
Comparison of the mechanical and physical properties of a carbon fibre epoxy composite manufactured by resin transfer moulding using conventional and microwave heating
}

\author{
D.A. Papargyris ${ }^{1,{ }^{*}}$, R.J. Day ${ }^{1}$, A. Nesbitt ${ }^{1}$, D.Bakavos ${ }^{2}$ \\ ${ }^{1}$ Northwest Composites Centre, University of Manchester, Sackville St., Manchester M60 1QD, UK \\ ${ }^{2}$ Manchester Materials Science Centre, University of Manchester, Grosvenor St., Manchester M1 7HS, \\ $U K$ \\ *corresponding author: email: D.Papargyris@ postgrad.manchester.ac.uk Tel.: +44 1613062255
}

\begin{abstract}
Microwave processing holds great potential for improving current composite manufacturing techniques, substantially reducing cure cycle times, energy requirements and operational costs. In this paper, microwave heating was incorporated into the resin transfer moulding technique. Through the use of microwave heating, a 50\% cure cycle time reduction was achieved. The mechanical and physical properties of the produced carbon fibre/epoxy composites were compared to those manufactured by conventional resin transfer moulding. Mechanical testing showed similar values of flexural moduli and flexural strength for the two types of composites after normalisation of the corresponding data to a common fibre volume fraction. A 9\% increase of the interlaminar shear strength (ILSS) was observed for the microwave cured composites. This enhancement in ILSS is attributed to a lowering of resin viscosity in the initial stage of the curing process, which was also confirmed via scanning electron microscopy by means of improved fibre wetting and less fibre pull-out. Furthermore, both types of composites yielded minimal void content $(<2 \%)$. Dynamic mechanical thermal analysis revealed comparable glass transition temperatures for composites produced by both methods. A $15^{\circ} \mathrm{C}$ shift in the position of the $\beta$-transition peak was observed between thermally and microwave cured composites, suggesting an alteration in the cross-linking path followed.
\end{abstract}

Keywords: Microwave curing; E. Resin transfer moulding; A. Polymer matrix composites; B. Interfacial strength; B. Mechanical properties 


\section{Introduction}

Fibre-reinforced polymer composites have gained substantial interest over the last years, mainly due to their very high strength-to-weight and stiffness-to-weight ratios. These properties led to the use and application of composite materials in a lot of major industries with the aerospace and automotive industry taking the larger part. The high operational costs involved in combination with the intricacy of the manufacturing techniques currently employed have restricted wider industrial use of composites. For that reason, considerable effort has been made in the direction of finding and developing alternative costeffective routes for curing composite materials.

One such alternative route is microwave processing, which offers several advantages over the conventional thermal processing methods, including rapid, selective and volumetric heating, energy savings, reduced processing time and improved processing control [1-4]. Microwave radiation generates heating within the material rather than relying on heat transfer through conduction and convection. It is, thus, more appropriate to consider microwave heating as conversion of electromagnetic energy to thermal energy rather than heat transfer [5]. A considerable amount of research has been devoted on microwave curing of different polymer [2, 6-13] and composite systems [14-23]. The implementation of microwave heating into common manufacturing methods for polymer composites, such as resin transfer moulding [24], however, has not yet been fully exploited.

The aim of the present work is to incorporate microwave heating into the resin transfer moulding technique and compare the overall physical and mechanical properties of the fabricated composites with those obtained by conventional thermal resin transfer moulding, in an attempt to assess the feasibility and efficiency of microwave radiation as an alternative power source for curing composites as well as determine any repercussions it might have on the attained composite properties and structure.

\section{Experimental}

\subsection{Materials}

The resin system used in this study was Araldite LY5052 / Aradur HY5052 (supplied by Huntsman). LY5052 is a low-viscosity epoxidised novolak resin and Aradur 5052 is a hardener comprising a mixture of polyamines. The resin/hardener mix ratio was 100:38 parts by weight. The reinforcement used was high strength T300 carbon fibre fabric (supplied by Hexcel Composites) with 
balanced 50/50 warp/weft five-harness satin weave architecture. Seven layers of carbon fibre reinforcement were used for each laminate panel.

\subsection{Resin transfer moulding (RTM) processing}

\subsubsection{Conventional thermal RTM processing}

Conventional thermal RTM processing was based on the Hypaject Mark II RTM Injection system (Plastech), as illustrated schematically in Fig.1. The system comprised an inlet valve, a heated homogenizer, a pneumatic valve, a metal mould with 16 electric-cartridge heaters ( 8 for each mould part) giving a total power output of $4 \mathrm{KW}$, two K-type thermocouples and two PID temperature controllers. Prior to the curing process, the metal mould was coated with Frekote 44-NC release agent. The fibres were then placed inside the mould cavity $(200 \times 300 \times 3 \mathrm{~mm}$ dimensions $)$ and the mould was inclined at $45^{0}$ from horizontal in a steel stand in order to minimize air entrapment during the injection.

The resin was drawn into the homogenizer through the inlet valve and left for 10-15 minutes under vacuum in order to remove any air bubbles created at the initial resin-hardener mixing stage. The resin was then injected under low pressure $(0.5$ bar $)$ into the mould through the inlet valve. After completion of the injection stage, the resin-loaded mould was heated for 3 hours at $100^{\circ} \mathrm{C}$ via the electriccartridge heaters, with the temperature controllers maintaining the desired cure temperature.

\subsubsection{Microwave RTM processing}

Microwave RTM processing differed from conventional thermal RTM processing in how the resin-loaded mould was heated after the injection stage. Instead of traditional thermal heating, microwave radiation was employed in order to cure the composites. Metal is known to reflect microwave energy, thus a moulding tool suitable for use inside the microwave field was manufactured from Macor. Macor is a machinable glass ceramic with good dielectric properties, exhibiting at room temperature a loss tangent and a dielectric loss of $7.1 \times 10^{-3}$ and $4 \times 10^{-2}$ at $8.5 \mathrm{GHz}$, and $4.7 \times 10^{-3}$ and $2.8 \times 10^{-2}$ at $1 \mathrm{KHz}$, respectively (as given by supplier, Precision Ceramics). These properties allowed microwave energy to be absorbed predominantly by the resin and not the mould material, whilst providing the required dimensional stability to withstand the temperature and pressure cycles during processing. The cavity dimensions of the Macor mould was 200 x 200 × $3 \mathrm{~mm}$. Preparation of the Macor mould prior to resin injection involved applying 
Chemlease C15 sealer agent and PMR Chemlease release agent. The fibres were then placed inside the cavity and the mould was again inclined at $45^{\circ}$ from horizontal during resin injection, which was carried out using the Hypaject RTM system described in 2.2.1.

The microwave RTM heating equipment comprised a network analyser (NA) (Hewlett Packard HP8720ET) used as the power source, a travelling wave tube (TWT) amplifier, an isolator, a multi-mode microwave applicator (brass cavity), a Macor RTM mould and 4 fluoroptic probes (Luxtron Corp.) connected to a Luxtron 790 fluoroptic thermometer. The microwave RTM system set-up is illustrated in Fig.2. The microwave signal from the NA was amplified by the TWT amplifier and then fed to the microwave applicator via an isolator in order to protect the TWT amplifier against any reflected power from the applicator. The maximum amplifier output power that could be used in this configuration was $250 \mathrm{~W}$.

A computer control system was employed to ensure both a uniform heating and maintain a stable cure temperature. Microwave power, excitation frequency and sample temperature were used as the process control parameters. Temperature stability was achieved by adjusting the microwave power while uniformity of the electric field distribution within the applicator was provided by varying the excitation frequency. Ten different excitation frequencies ranging from 4-8 GHz were used for processing. These frequencies were dictated by the microwave response of the applicator loaded with the Macor moulding tool, resin and carbon fibre reinforcement just before curing and were selected in order to minimise the reflected power.

Microwave power and frequency were adjusted via a General Purpose Interface Bus (GPIB) connection between the computer and the NA. The computer control system was designed in such way that the NA would continuously step through the excitation frequencies, while simultaneously regulating the microwave power in order to maintain the desired cure temperature. The sample temperature was constantly monitored by the computer via a serial connection (RS-232) with the fluoroptic thermometer. The computer control system regulated the microwave power according to the following quadratic algorithm:

$$
\text { Power } \propto\left[\frac{T_{\text {cure }}-T}{T_{\text {cure }}-T_{\min }}\right]^{2}
$$


where, $\mathrm{T}$ was the maximum of the measured sample temperatures, $\mathrm{T}_{\text {cure }}$ was the cure temperature and $\mathrm{T}_{\min }$ was a pre-set temperature limit. As can be seen from Eq.1, the amplifier output power used was proportional to the square of the difference between the set cure temperature and the actual temperature. At temperatures below $\mathrm{T}_{\min }$ full power was applied, whereas when the temperature exceeded $\mathrm{T}_{\text {cure }}$ the power was turned off.

\subsection{Mechanical testing}

\subsubsection{Flexural modulus and flexural strength}

The flexural properties of the composite samples were determined according to ASTM Standard D 6272 [25]. The apparatus used was an Instron 4301 equipped with a four-point bend jig and a $5 \mathrm{KN}$ load cell. For each composite panel six samples were tested and an average value was taken.

\subsubsection{Interlaminar shear strength}

Interlaminar shear testing of the composite samples was conducted on an Instron 4301 equipped with a three-point bend jig and a 5 KN load cell, according to ASTM Standard D 2344/D 2344M [26]. For each composite panel eight samples were tested and an average value was taken.

\subsection{Fibre and void volume fraction}

The percentage fibre volume fraction $V_{r}$ and the percentage void volume fraction $V_{v}$ were determined using matrix digestion with nitric acid in a microwave oven according to ASTM Standard D 3171 [27]. Prior to that, the density of the samples was determined according to Airbus UK Test Specification [28]. For each panel ten samples were tested and an average value was taken.

\subsection{Rheology}

The viscosity of the neat LY/HY5052 resin system was determined as a function of time using a RMS 800 rheometer. The neat resin was heated between two parallel $50 \mathrm{~mm}$ aluminium plates under a 1 $\mathrm{Hz}$ oscillating frequency at $2^{\circ} \mathrm{C} / \mathrm{min}, 5^{\circ} \mathrm{C} / \mathrm{min}$ and $10^{\circ} \mathrm{C} / \mathrm{min}$ from room temperature until gelation occurred. 


\subsection{Differential scanning calorimetry (DSC)}

Differential scanning calorimetric studies were carried out on a TA Instruments MDSC 2920 to ensure that the fabricated composite panels were fully cured. Small size samples $(<10 \mathrm{mg})$ were heated from $20^{\circ} \mathrm{C}$ up to $250^{\circ} \mathrm{C}$ at $10^{\circ} \mathrm{C} / \mathrm{min}$ in an inert nitrogen atmosphere. Samples were taken from different locations on each composite panel.

\subsection{Dynamic mechanical thermal analysis (DMTA)}

Dynamic mechanical thermal analysis was carried out on a TA Instruments DMA Q800 to obtain the glass transition temperatures for both conventional thermal and microwave cured composites. The composite samples $(60 \times 8 \times 3 \mathrm{~mm})$ were heated from $-120^{\circ} \mathrm{C}$ up to $250^{\circ} \mathrm{C}$ at $2^{\circ} \mathrm{C} / \mathrm{min}$ while the frequency of the applied oscillating stress was $1 \mathrm{~Hz}$. For each composite panel six samples were tested.

\subsection{Scanning electron microscopy (SEM)}

The composite samples were examined using Philips XL30 FEG SEM microscope. Small sections of the fracture surfaces were cut from test samples subjected to mechanical testing and placed on metal stubs using double-sided carbon tabs. The stubs with the fracture surfaces were then coated with a very thin layer of gold using Edwards S150B sputter coater in order to make them electrically conductive.

\section{Results and discussion}

Based on previous work by Yusoff [29], the cure cycle employed for conventional thermal processing was $100^{\circ} \mathrm{C}$ for 3 hours. DSC results confirmed that the composite panels fabricated using this profile were fully cured. Determination of the cure cycle for microwave processing was based on the dielectric properties of the neat resin, as they were measured according to the cavity perturbation technique [30]. Fig. 3 shows the evolution of the dielectric loss and dielectric constant of the neat resin at $100^{\circ} \mathrm{C}$ and $2.45 \mathrm{GHz}$ as a function of time.

The measurement of the dielectric properties was carried out at a set frequency of $2.45 \mathrm{GHz}$ and without taking into consideration the effect of the carbon fibre reinforcement. However, these properties should be indicative of the dielectric response of the composite system at the desired curing temperature. Given that the absorbed microwave power is proportional to the dielectric loss of the material inside the 
microwave field, it can be assumed that the curing reaction has concluded once the dielectric loss reaches a constant value over time. As depicted in Fig.3, the dielectric loss stabilised after about 90 minutes, thus the cure cycle employed for microwave processing was 90 minutes at $100^{\circ} \mathrm{C}$. DSC analysis of the composite panels produced by microwave RTM under the selected cure cycle showed that the samples were fully cured, indicating sufficient cure cycle time as well as uniform microwave field distribution inside the applicator; otherwise localized hot spots within the field would have resulted in composite panels with inferior mechanical and physical properties, owing to uneven degrees of cure.

This $50 \%$ cure cycle time reduction between conventional and microwave RTM processing was achieved due to the different nature of interaction between the resin and microwave radiation, which in turn yields a different heating mechanism compared to conventional thermal heating. Generally, microwave heating is regarded as a volumetric heating technique in which the microwaves interact with the material and heat is generated directly as a result. Hence heating is efficient, because energy is deposited directly into the material and the effects of convective and conduction heat transfer are less significant than with some other heating techniques. In carbon fibre composites, the situation is probably more complicated as the skin depth is very small. Calculations based on the dielectric data measured for Hexply 6376 by Atkinson [31] show that the skin depth at the frequencies used in the present work is between 0.5 and $2.2 \mathrm{~cm}$. While the resin and fibre system used by Atkinson were different it is likely that the apparent dielectric properties were dominated by the conductivity of the carbon fibre and that the skin depth for the system used in this study is similar. Therefore, the microwaves do not penetrate a long way into the composite at all frequencies. They interact instead with a surface layer. This means that there is still good heat transfer into the surface of the composite. Within the composite it is likely that the microwave electric field generates an electric current in the carbon fibres and thus resistive heating. Resin will be heated through dielectric heating at the surface of the composite. Within the bulk it will be heated due to the resistive heating of the fibres and through thermal conduction. The cure cycle required for microwave heating in this work was half than that needed for conventional thermal heating, suggesting that despite the likely skin depth heat transfer through microwave heating is still faster than through conventional heating.

The key question, therefore, is whether this substantial cutback in the cure cycle time of the microwave cured composites would have any detrimental effect on their overall mechanical and physical 
properties. Table 1 shows the average values of flexural modulus, flexural strength, interlaminar shear strength, fibre volume fraction, void content and panel thickness obtained for composite panels manufactured by both conventional thermal and microwave RTM processing. The average panel thickness of the microwave cured composite panels was slightly higher compared to those cured thermally due to small dimensional differences of the Macor mould cavity attained at machining. For that reason, given the same number of carbon fibre layers used to manufacture composites with both methods, the microwave cured samples exhibited slightly lower fibre volume fraction, as they contained more resin per unit volume.

In order to compare the flexural mechanical properties of the manufactured composites, the mechanical data for the microwave RTM composites were normalised to an equivalent fibre volume fraction of $33 \%$. The normalised values are tabulated in Table 1 . The normalisation was carried out assuming a linear relationship between fibre volume fraction and flexural strength and modulus. The flexural moduli of both thermally and microwave cured composites were found to be comparable. A small increase in the flexural strength of the microwave cured composites was observed. Nevertheless, this increase is within the experimental error involved in measuring; no distinctive improvement in the flexural strength of the microwave cured samples can be concluded, with both types of composites exhibiting equivalent flexural properties. The value, however, of the interlaminar shear strength obtained for the composites fabricated via microwave RTM yields a very interesting result. As can be seen in Table 1, the interlaminar shear strength for the microwave cured samples was found to be $9 \%$ higher than those cured thermally, possibly signifying that microwave processing improves the interfacial bonding between epoxy resin and carbon fibre reinforcement. This is in agreement with other work by Fang [32] and Rao [18].

The enhancement in the interlaminar shear strength can be ascribed to a lowering in the resin viscosity at the initial curing stage of microwave processing, before the cross-linking density starts to rise rapidly and the resin becomes very viscous; in which case no significant change in the composite physical properties could occur. Previous work suggests that by lowering the resin viscosity, improved resin-fibre adhesion and fibre wet-out can be achieved [33-35]. Fig. 4 shows the viscosity change against time at 3 different heating rates $\left(2^{\circ} \mathrm{C} / \mathrm{min}, 5^{\circ} \mathrm{C} / \mathrm{min}\right.$ and $\left.10^{\circ} \mathrm{C} / \mathrm{min}\right)$ for the neat $\mathrm{LY} / \mathrm{HY} 5052$ resin system. As the heating rate increased the minimum viscosity of the neat resin decreased considerably from $0.12 \mathrm{~Pa}$-s to 
$0.068 \mathrm{~Pa}-\mathrm{s}$ and finally to $0.043 \mathrm{~Pa}$-s. Microwave heating is known to be rapid and volumetric, generating heat within the material, mainly due to ionic polarization and dipole orientation $[1,36]$, rather than relying on heat transfer through conduction or convection, although the effect in carbon fibre composites is more complicated, as noted earlier. A higher heating rate would result in a decrease in the resin viscosity, which in turn would facilitate resin flow, making it easier for the resin to impregnate the carbon fibre surface during the initial stage of the curing process. A lower viscosity would improve the interfacial bonding and enhance the mechanical interlocking between the resin and the fibres. The increase in the interlaminar shear strength could be also partly attributed to extended plastic deformation and hence increased crack-tip blunting, as a result of the greater amount of resin between the fibre layers in the microwave cured samples compared to those cured thermally, given the lower fibre volume fraction of the former. In addition, the improvement in the resin flow has a direct effect on the void content obtained for the microwave cured composites, as shown from the low void content value of $0.6 \%$ (Table 1 ). The fluidity of the resin is thought to provide better contact between the resin and the fibre surface contour, allowing the resin to effectively enter any formed micro-holes which where previously occupied by trapped air. However, panels produced conventionally also yielded an acceptable low void content of $1.7 \%$.

Typical DMTA curves at $2^{\circ} \mathrm{C} / \mathrm{min}$ scan rate and $1 \mathrm{~Hz}$ frequency for the thermally and microwave cured composites are illustrated in Figs. 5 and 6. Regarding the average peak values of the higher temperature $\alpha$-transition, no significant differences existed for both types of composites, with the microwave cured samples exhibiting a slightly higher glass transition temperature $\left(\mathrm{T}_{\mathrm{g}}\right)$ of $130 \pm 1{ }^{\circ} \mathrm{C}$, as opposed to $128 \pm 2{ }^{\circ} \mathrm{C}$ for those cured thermally. However, a $15^{\circ} \mathrm{C}$ difference in the average peak values of the lower temperature $\beta$-transition was observed between the two composite types $\left(-72 \pm 3{ }^{\circ} \mathrm{C}\right.$ and -57 $\pm 3{ }^{\circ} \mathrm{C}$ for the thermally and microwave cured composites respectively). The low $\beta$-transition in epoxy systems has been observed between $-80^{\circ} \mathrm{C}$ to $-40^{\circ} \mathrm{C}$ [37-39]. More specific in epoxy-amine curing, lowtemperature relaxations are mainly associated with the molecular motion of the hydroxyether portion of the molecule [40]. A possible difference in the molecular structure of the polymer chain could, hence, account for the shift in the position of the $\beta$-transition peak, which in turn might be caused by an alteration in the cross-linking path followed between the microwave and the thermally produced composites. 
The fracture surfaces of composite samples subjected to four-point bending and interlaminar shear testing were also examined using scanning electron microscopy. Representative topographic features of both types of composites are shown in Figs. 7-9. Careful examination of the fracture surface morphology of thermally and microwave cured samples revealed some differences between the two types of composites. It can be seen from Figs. $7 \mathrm{a}$ and $7 \mathrm{~b}$, that the fracture surface of the composites produced with the conventional method exhibits poorer interfacial bonding and more extensive fibre pull-out compared to that produced using microwaves. This is more obvious in Figs. 8a and 8b, where there is a significant amount of clean fibres present as opposed to fibres thoroughly coated with resin, for the thermally and microwave cured composites respectively. Brittle matrix failure regions were also identified for both types of composites, as shown in Figs. 9a and 9b. However, due to the complexity of woven fabric composites compared to unidirectional composites, the interlaminar fracture behaviour under Mode I, Mode II and mixed Mode I and II loading could also be investigated in order to have a more in depth understanding of the main failure modes.

\section{Conclusions}

A modification of the conventional RTM method incorporating the use of microwave heating was presented. A ceramic moulding tool with dielectric properties suitable for use inside the microwave field was manufactured. The method was based on the Hypaject Mark II RTM Injection system. The microwave heating equipment comprised a network analyser, a travelling wave tube amplifier, an isolator, a multi-mode applicator and optical temperature sensing. Composites were produced by both conventional thermal and microwave RTM processing in order to compare their physical and mechanical properties.

The curing profile employed in conventional RTM processing was 3 hours at $100^{\circ} \mathrm{C}$ as opposed to 90 minutes at $100^{\circ} \mathrm{C}$ in microwave RTM processing, resulting to a $50 \%$ cure cycle time reduction through the use of microwave heating. DSC analysis of samples taken from different panel locations confirmed that the microwave cured composites were fully cured, validating the uniformity of the microwave field inside the applicator. Mechanical testing showed similar values of flexural moduli obtained for the two types of composites. A small increase in the flexural strength of the microwave cured composites was observed. However, this increase is not profound as it falls within the experimental error. 
The interlaminar shear strength of the composites produced by microwave RTM processing was found to be $9 \%$ higher than that of the thermally cured composites. This enhancement is suggested to be mainly attributed to a lowering of resin viscosity at the initial stage of the curing process due to a higher heating rate, which in turn facilitated the resin flow and improved the interfacial bonding between the resin and the fibre surface. Examination of the composite fracture surface morphology, as illustrated by a series of SEM micrographs of specimens failed after mechanical testing, provided additional evidence of improved interfacial bonding in terms of increased fibre wetting, less fibre pull-out, and better coating of the fibres with resin for the microwave cured specimens compared to those cured thermally. Both microwave and thermally cured composites yielded minimal void contents $(<2 \%)$, as indicated by the results from the hot acid digestion method. The microwave cured composites exhibited lower void content values than those cured conventionally. DMTA analysis of composites produced by both methods revealed similar glass transition temperatures $\left(\mathrm{T}_{\mathrm{g}}\right)$ for the higher temperature $\alpha$-transition $\left(128 \pm 2{ }^{\circ} \mathrm{C}\right.$ and $130 \pm 1{ }^{\circ} \mathrm{C}$ for the conventionally and microwave cured composites respectively). However, a significant shift of about $15^{\circ} \mathrm{C}$ in the position of the $\beta$-transition peak was observed between the two types of composites, probably due to an alteration in the cross-linking path followed.

The results presented in this work underline the potential of microwave heating in improving composite processing and manufacture. Despite the half cure cycle time employed, the mechanical and physical properties of the microwave cured composites were found to be similar and, in some cases, superior compared to their thermally cured counterparts. However, further research is necessary in order to understand and explain the differences in the reaction mechanism between thermally and microwave cured composites.

\section{Acknowledgement}

The authors would like to thank Hexcel Composites and Huntsman for supplying the carbon fibres and the epoxy resin, respectively.

\section{References}

1. Mijovic J, Wijaya J. Review of cure of polymers and composites by microwave energy. Polymer Composites 1990; 11:184-191. 
2. Zhou J, Shi C, Mei B, et al. Research on the technology and the mechanical properties of the microwave processing of polymer. Journal of Materials Processing Technology 2003; 137(13):156-158.

3. Ku HS, Siores E, Taube A, Ball JAR. Productivity improvement through the use of industrial microwave technologies. Computers \& Industrial Engineering 2002; 42(2-4):281-290.

4. Bykov YV, Rybakov KI, Semenov VE. High-temperature microwave processing of materials. Journal of Physics D: Applied Physics 2001; 34(13):R55-R75.

5. Thostenson ET, Chou T-W. Microwave processing: fundamentals and applications. Composites Part A: Applied Science and Manufacturing 1999; 30(9):1055-1071.

6. Wei J, Hawley MC, Delong JD. Comparison of Microwave and Thermal Cure of Epoxy resins. Polymers Engineering and Science 1993; 33(17):1132-1140.

7. Bai SL, Djafari V, Andreani M, Francois D. A comparative study of the mechanical behaviour of an epoxy resin cured by microwaves with one cured thermally. European Polymer Journal 1995; 31(9):875-884.

8. Mijovic J, Wijaya J. Comparative calorimetric study of epoxy cure by microwave vs thermal energy. Macromolecules 1990; 23(15):3671-3674.

9. Marand E, Baker KR, Graybeal JD. Comparison of reaction mechanisms of epoxy resins undergoing thermal and microwave cure from in situ measurements of microwave dielectric properties and infrared spectroscopy. Macromolecules 1992; 25(8):2243-2252.

10. Fu B, Hawley MC. Comparative Study of Continuous-Power and Pulsed-Power Microwave Curing of Epoxy Resins. Polymer Engineering and Science 2000; 40(10):2133.

11. Boey FYC, Yap BH. Microwave curing of an epoxy-amine system: effect of curing agent on the glass-transition temperature. Polymer Testing 2001; 20(8):837-845.

12. Rahmat AR, Heatley F, Day RJ. Comparison of microwave and thermal cure of unsaturated polyester resin. Plastics, Rubber and Composites 2003; 32(6):257-264.

13. Ismail Z, Day R, Heatley F. Comparison between the thermal and microwave curing of bismaleimide resin. Journal of Applied Polymer Science 2003; 90(10):2764-2774.

14. Boey FYC, Lee WL. Microwave radiation curing of a thermosetting composite. Journal of Materials Science Letters 1990; 9:1172-1173. 
15. Yue CY, Looi HC. Influence of thermal and microwave processing on the mechanical and interfacial properties of a glass/epoxy composite. Composites 1995; 26(11):767-773.

16. Nightingale C, Day RJ. Flexural and interlaminar shear strength properties of carbon fibre/epoxy composites cured thermally and with microwave radiation. Composites Part A: Applied Science and Manufacturing 2002; 33(7):1021-1030.

17. Qiu Y, Hawley M. Composite Material Processing in a Single Mode Cavity with Variable Frequency Microwaves. 12th International Conference on Composite Materials. Paris, France, July, 1999.

18. Rao R, Rao S, Sridhara B. Studies on Tensile and Interlaminar Shear Strength Properties of Thermally Cured and Microwave Cured Glass-Epoxy Composites. Journal of Reinforced Plastics and Composites 2006; 25(7):783.

19. Varaporn T, Kaew S. Comparison of microwave and thermal cure of epoxy-anhydride resins: Mechanical properties and dynamic characteristics. Journal of Applied Polymer Science 2005; 97(4):1442-1461.

20. Varaporn T, Dumrong J. Comparison between microwave and thermal curing of glass fiberepoxy composites: Effect of microwave-heating cycle on mechanical properties. Journal of Applied Polymer Science 2006; 102(2):1059-1070.

21. Thostenson ET, Chou T-W. Microwave and conventional curing of thick-section thermoset composite laminates: Experiment and simulation. Polymer Composites 2001; 22(2):197-212.

22. Boey FYC, Lee TH. Electromagnetic radiation curing of an epoxy/fibre glass reinforced composite. International Journal of Radiation Applications and Instrumentation. Part C. Radiation Physics and Chemistry 1991; 38(4):419-423.

23. Mooteri PS, Sridhara B, Rao S, et al. Studies on mechanical behavior of microwave and thermally cured glass fiber reinforced polymer composites. Journal of Reinforced Plastics and Composites 2006; 25(5):503-512.

24. Johnson MS, Rudd CD, Hill DJ. Microwave assisted resin transfer moulding. Composites Part A: Applied Science and Manufacturing 1998; 29(1-2):71-86.

25. ASTM D 6272 Standard test method for flexural properties of unreinforced and reinforced plastics and electrical insulating materials by four-point bending, 2002. 
26. ASTM D 2344/D 2344M Standard test method for short-beam strength of polymer matrix composite materials and their laminates, 2000.

27. ASTM D 3171 Standard test method for constituent content of composite materials, 1999.

28. Airbus UK Test Specification, ABT 1-0018, 2003.

29. Yusoff R. Microwave assisted RTM processing of carbon/epoxy composites. PhD Thesis, The University of Manchester, 2004.

30. Nesbitt A, Navabpour P, Degamber B, et al. Development of a microwave calorimeter for simultaneous thermal analysis, infrared spectroscopy and dielectric measurements. Measurement Science and Technology 2004; 15(11):2313-2324.

31. Atkinson AG. Investigation of potential methods for improved processing of carbon/epoxy composites. PhD Thesis, The University of Manchester, 2005.

32. Fang X, Scola DA. Investigation of microwave energy to cure carbon fiber reinforced phenylethynyl-terminated polyimide composites, PETI-5/IM7. Journal of Polymer Science Part A: Polymer Chemistry 1999; 37(24):4616-4628.

33. Huang YD, Liu L, Qiu JH, Shao L. Influence of ultrasonic treatment on the characteristics of epoxy resin and the interfacial property of its carbon fiber composites. Composites Science and Technology 2002; 62(16):2153-2159.

34. Liu L, Huang Y, Zhang Z, Yang X. Effect of ultrasound on wettability between aramid fibers and epoxy resin. Journal of Applied Polymer Science 2006; 99(6):3172.

35. Davies LW, Day RJ, Bond D, et al. Effect of cure cycle heat transfer rates on the physical and mechanical properties of an epoxy matrix composite. Composites Science and Technology; In Press, Corrected Proof.

36. Decareau RV, Peterson RA. Microwave Processing and Engineering: Ellis Horwood Ltd. and VCH Verlagsgesellschaft mbH, 1986.

37. Shimbo M, Ochi M, Iesako H. Mechanical relaxation mechanism of epoxide resins cured with acid anhydrides. Journal of Polymer Science Polymer Physics Edition 1984; 22(8):1461-1470.

38. Ochi M, Shimbo M, Saga M, Takashima N. Mechanical and dielectric relaxations of epoxide resins containing spiro-ring structure. Journal of polymer science. Polymer physics edition 1986; 24(10):2185-2195. 
39. Pogany GA. Gamma relaxation in epoxy resins and related polymers. Polymer 1970; 11(2):6678.

40. Ochi M, Okazaki M, Shimbo M. Mechanical relaxation mechanism of epoxide resins cured with aliphatic diamines. Journal of Polymer Science Polymer Physics Edition 1982; 20(4):689-699.

Fig.1. Schematic of conventional thermal RTM processing (solid arrows indicate resin flow, dotted arrows indicate process control).

Fig.2. Schematic of microwave RTM processing (solid arrows indicate microwave power flow, dotted arrows indicate process control / temperature measurements).

Fig.3. Dielectric constant and dielectric loss of neat LY/HY5052 resin system measured at $100^{\circ} \mathrm{C}$ and $2.45 \mathrm{GHz}$ as a function of time.

Fig.4. Viscosity versus time at $2^{\circ} \mathrm{C} / \mathrm{min}, 5^{\circ} \mathrm{C} / \mathrm{min}$ and $10^{\circ} \mathrm{C} / \mathrm{min}$ for neat $\mathrm{LY} / \mathrm{HY} 5052$ resin system.

Fig.5. Storage modulus, loss modulus and tangent delta for the LY/HY5052/carbon composite system cured by conventional thermal RTM.

Fig.6. Storage modulus, loss modulus and tangent delta for the LY/HY5052/carbon composite system cured by microwave RTM.

Fig.7. SEM micrographs at same magnification showing fibre pull-out after four-point bending test; a) conventionally cured specimen b) microwave cured specimen.

Fig.8. SEM micrographs at same magnification after interlaminar shear test showing; a) clean fibres in conventionally cured specimen b) fibres coated with resin in microwave cured specimen

Fig.9. SEM micrographs at same magnification showing matrix fracture after interlaminar shear test; a) conventionally cured specimen b) microwave cured specimen. 


\begin{tabular}{lccc}
\hline & Conventional Thermal RTM & Microwave RTM & $\begin{array}{c}\text { Microwave RTM } \\
\left(\text { Normalised to 33\% } \mathrm{V}_{\mathrm{r}}\right)\end{array}$ \\
\hline Flexural Modulus $E_{B}(\mathrm{GPa})$ & $44 \pm 1$ & $37 \pm 2$ & 45.2 \\
Flexural strength $S(\mathrm{MPa})$ & $536 \pm 40$ & $475 \pm 27$ & 580 \\
ILSS $(\mathrm{MPa})$ & $50 \pm 1$ & $54.5 \pm 1$ & 27 \\
Fibre volume fraction $V_{r}(\%)$ & 33 & 0.6 & - \\
Void content $V v(\%)$ & 1.7 & $3.74 \pm 0.11$ & - \\
Panel thickness $(\mathrm{mm})$ & $3.38 \pm 0.08$ & & - \\
\hline
\end{tabular}

Table 1

Mechanical and physical properties of LY/HY5052/carbon composites produced by conventional thermal and microwave RTM processing. 
Fig.1

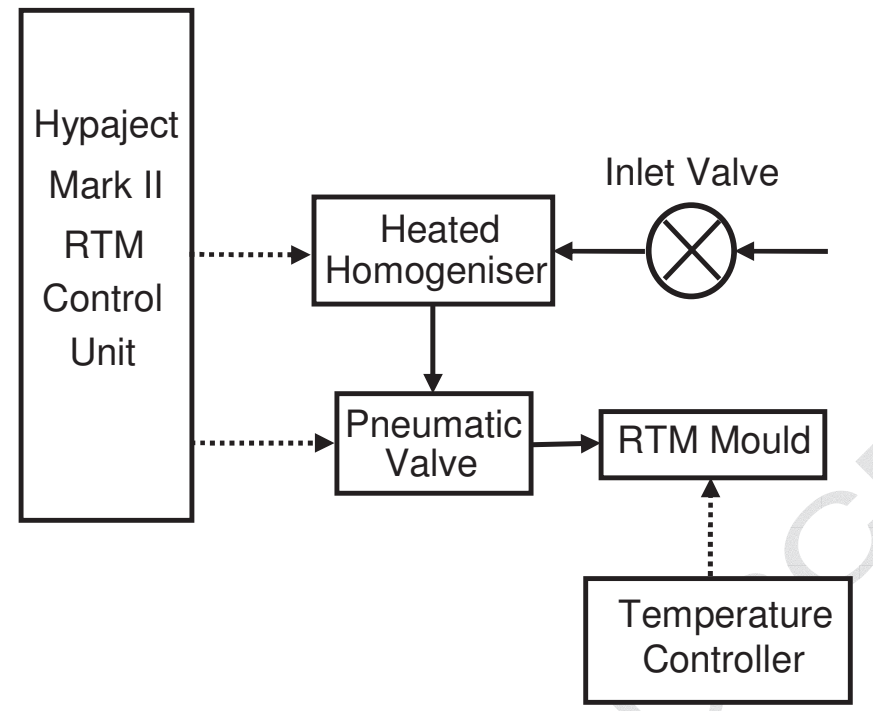


Fig.2

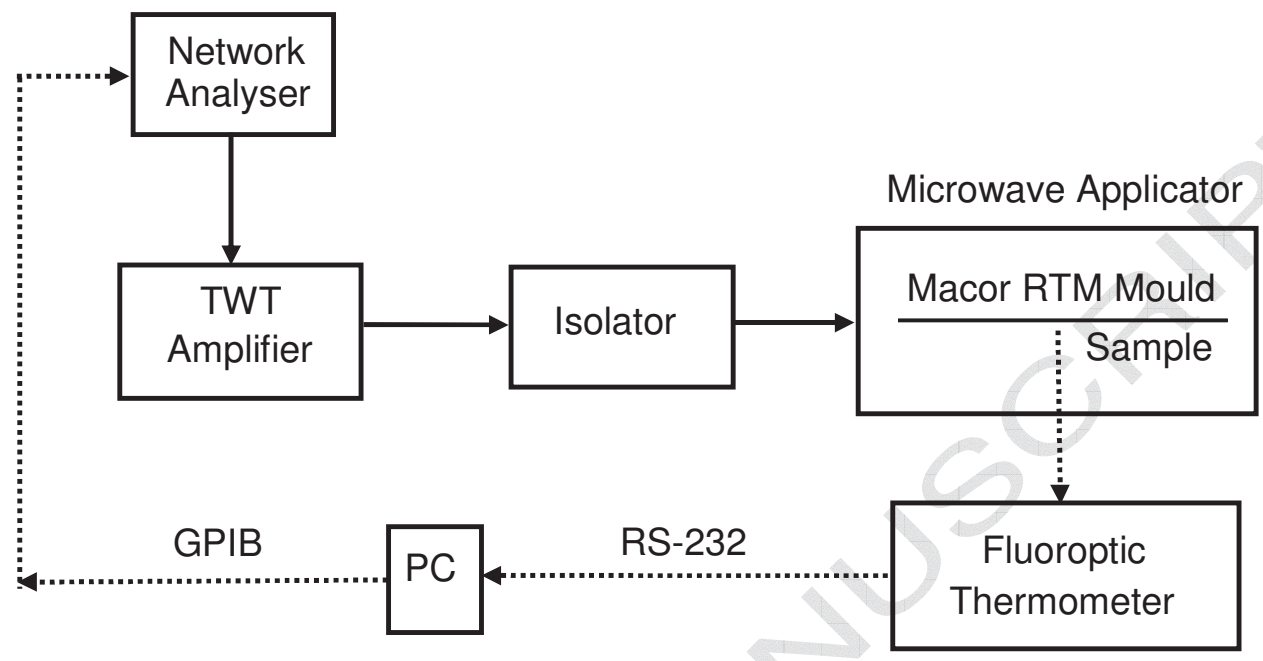




\section{ACCEPTED MANUSCRIPT}

Fig. 3

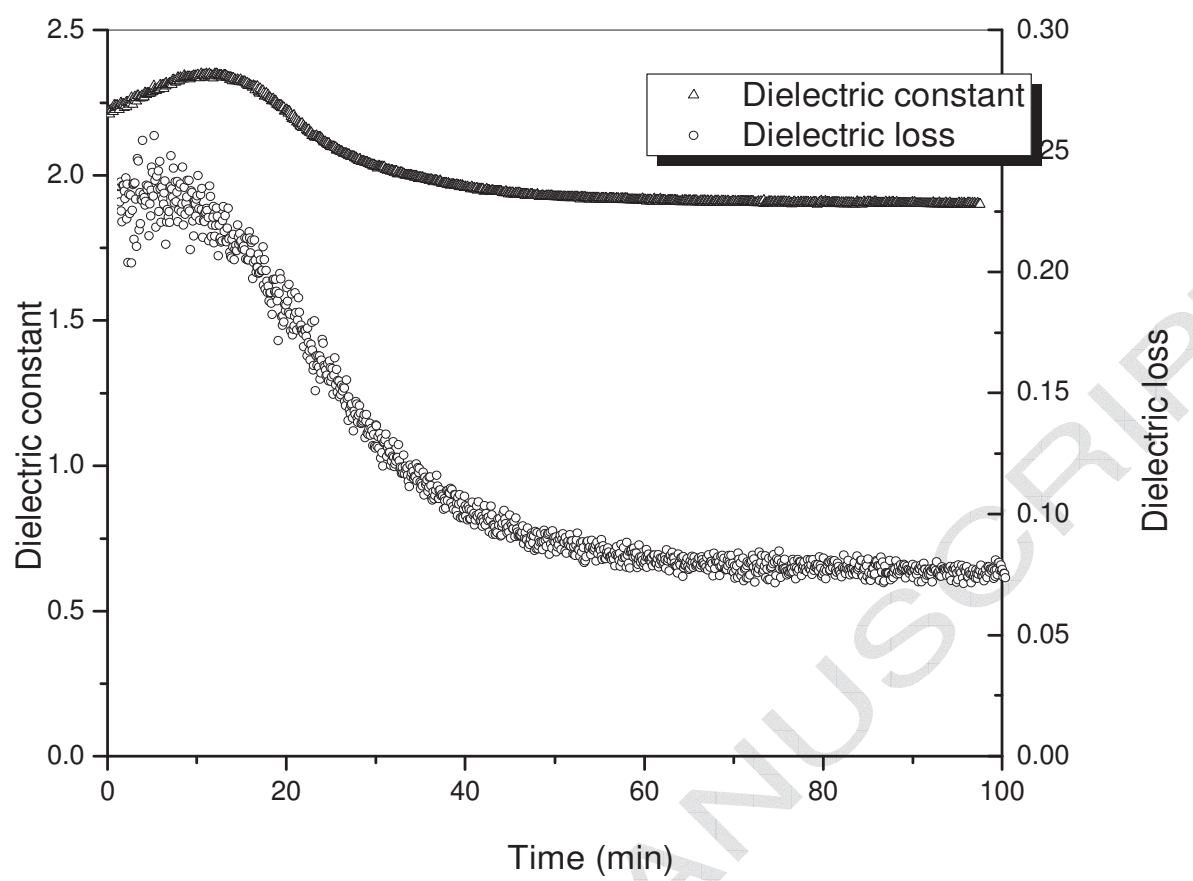


Fig.4

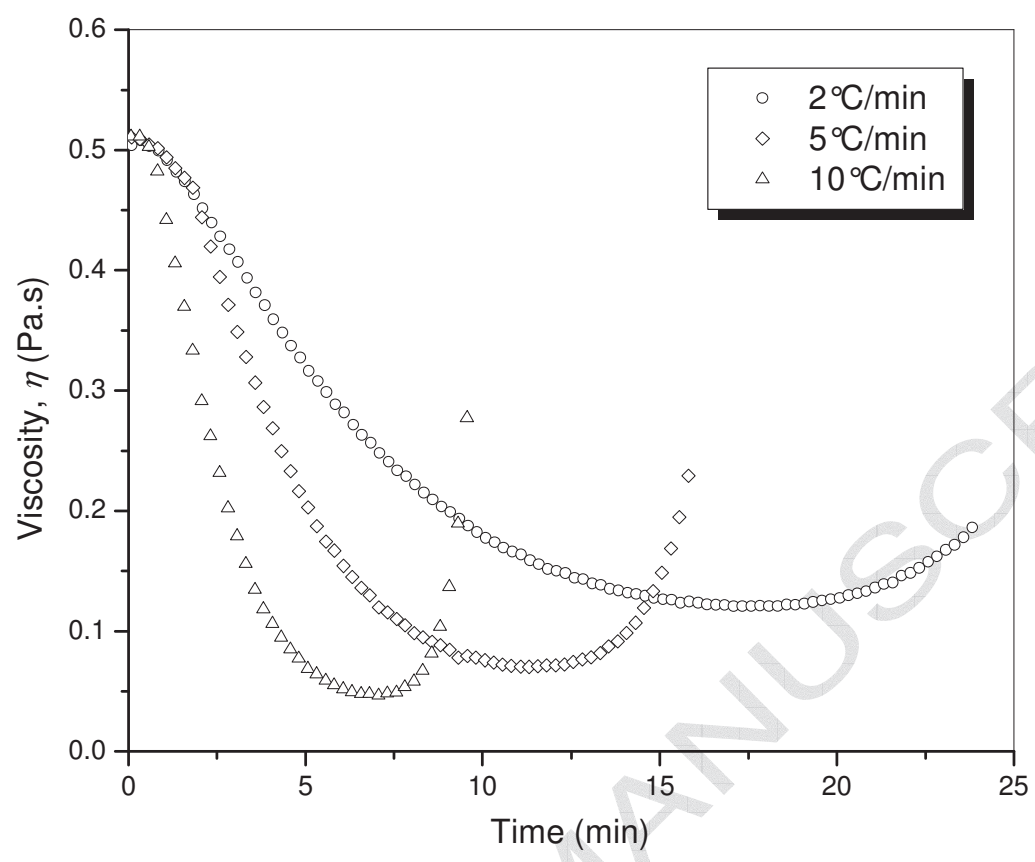


Fig. 5

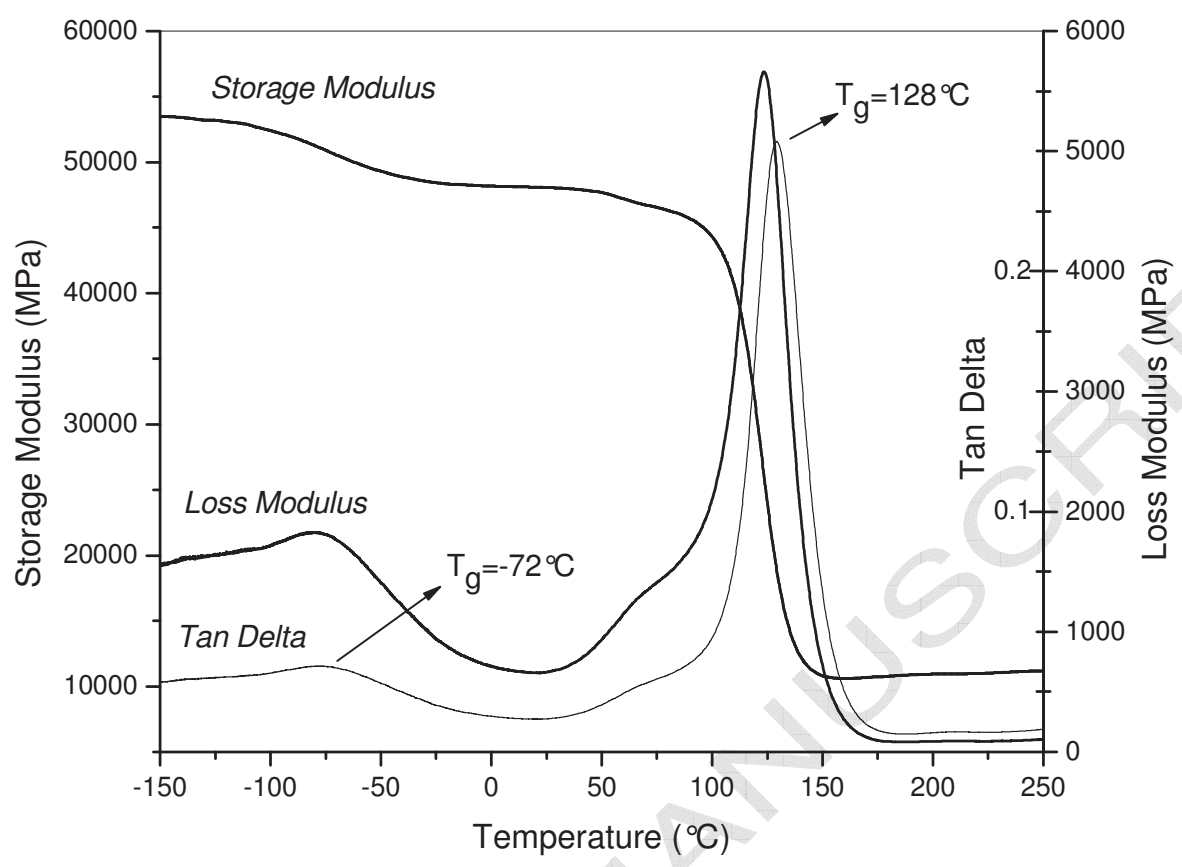


Fig.6

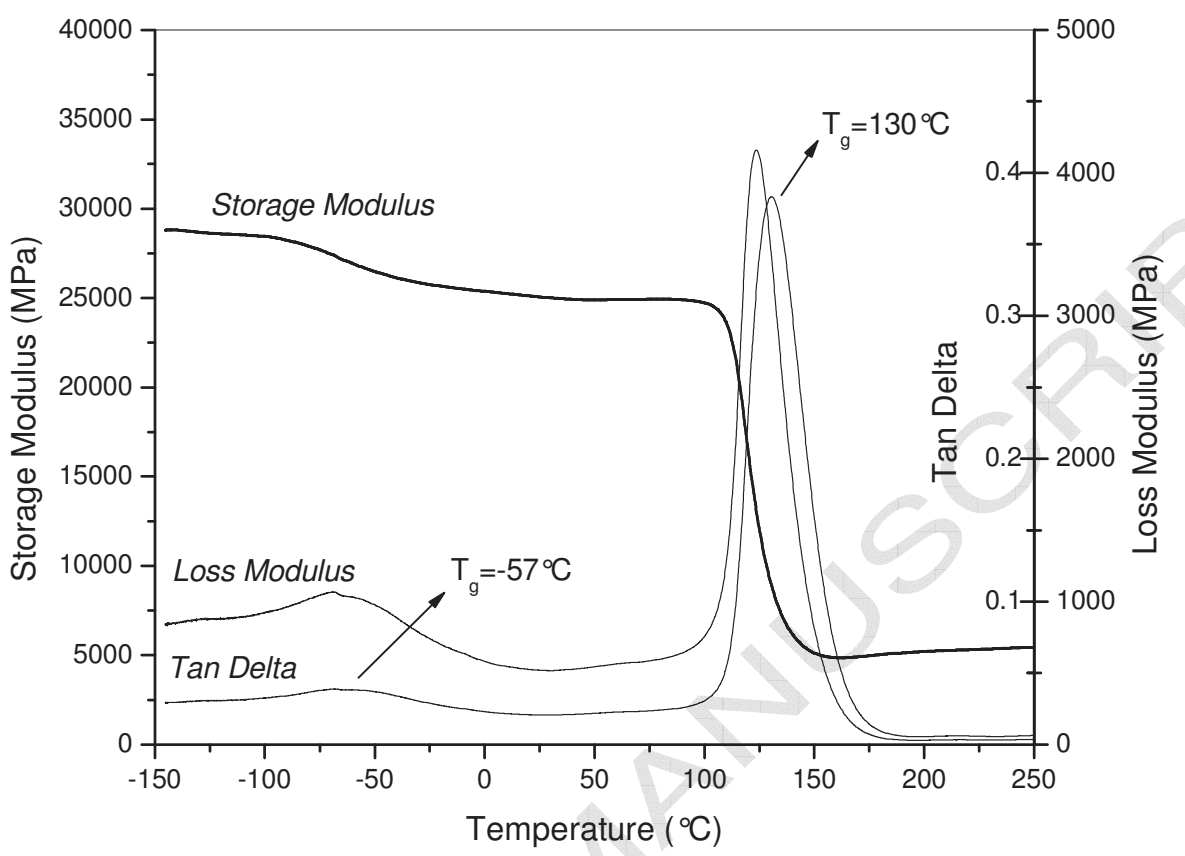




\section{ACCEPTED MANUSCRIPT}

Fig.7
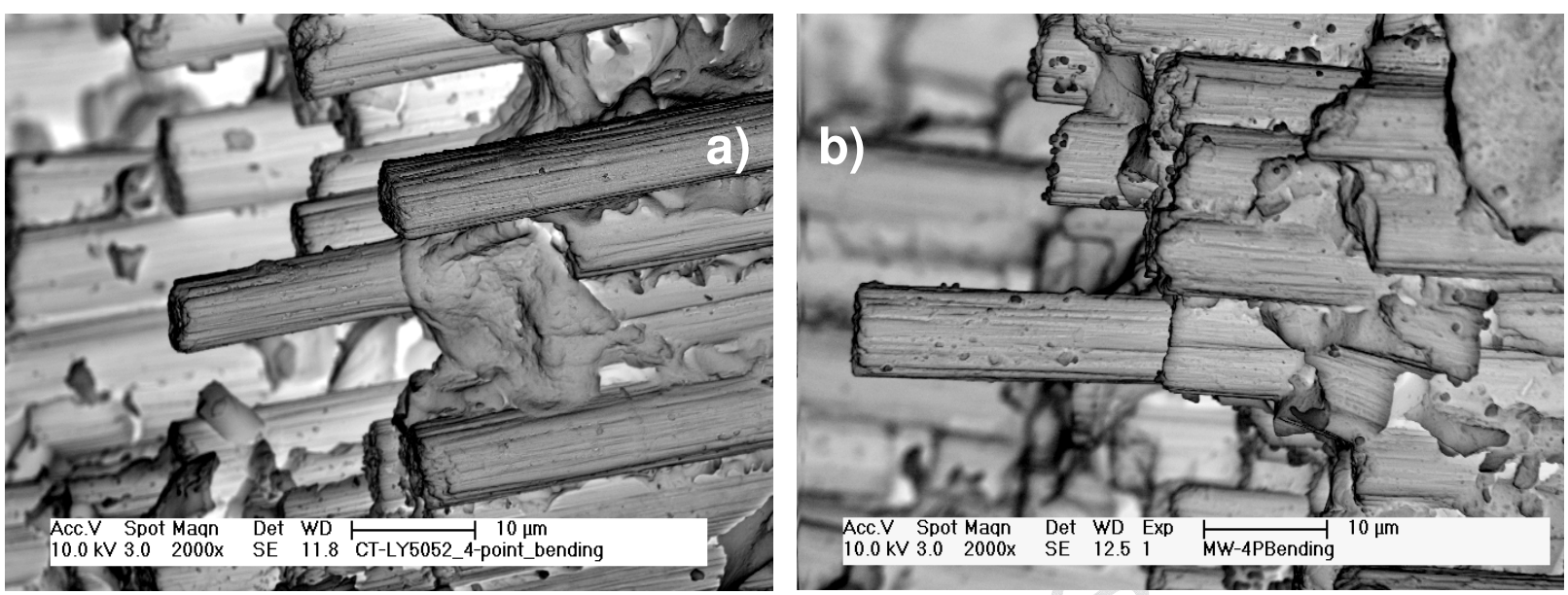
Fig. 8
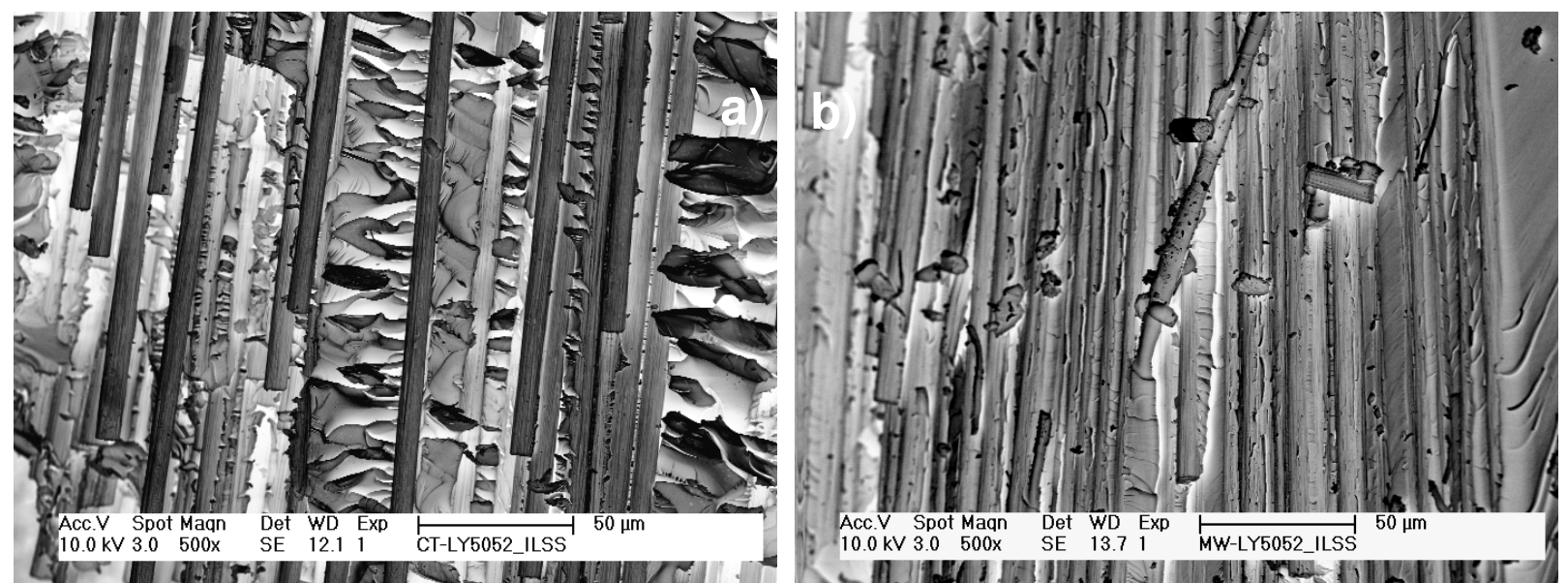
Fig.9
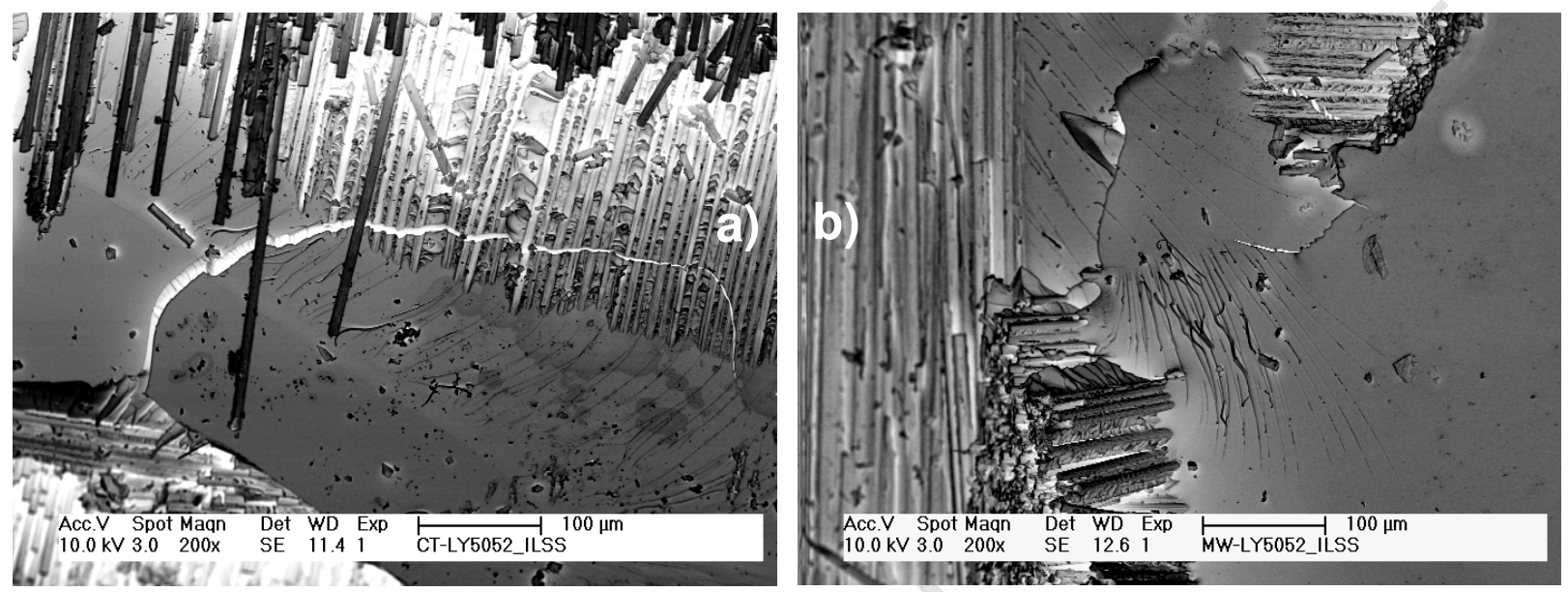